\title{
Ivermectina no tratamento de camundongos (Mus muscullus) infestados por ácaros
}

\author{
Ivermectin for the treatment of mice (Mus muscullus) infected by mites \\ Lucas Trevisan Gressler ${ }^{1}$, Aleksandro Schafer da Silva², Tayana Sessegolo', Maria Ester Bürguer ${ }^{3}$ \& Silvia \\ Gonzalez Monteiro ${ }^{4}$
}

\begin{abstract}
RESUMO
A utilização de animais de laboratório em pesquisa é uma prática comumente empregada, porém estes estudos podem ser afetados pelas condições ambientais e infecciosas. Este estudo visou relatar a infestação mista por ectoparasitos em camundongos (Mus muscullus) mantidos em um biotério experimental e testar um protocolo terapêutico no controle dos parasitos. Em 20 animais foi observado pelo seco, áreas de alopecia com lesões avermelhadas e úmidas, prurido intenso e crostas na região dorsal do corpo. Dos camundongos avaliados, foi coletado pelo e realizado raspado cutâneo para análise microscópica, onde se identificou nesses roedores ácaros das espécies Radfordia affinis, Myocoptes musculinus e Demodex sp. Os roedores foram separados em dois grupos, sendo que os animais do grupo A foram tratados com ivermectina $1 \%$ diluída em água na dose de $0,007 \mathrm{mg} \cdot \mathrm{ml}^{-1}$ por cinco dias consecutivos e os do grupo B não foram tratados. Após 10 dias do início do tratamento, no grupo A não foram encontrados ácaros, já no grupo B o número de ectoparasitos e as lesões de pele aumentaram. Portanto, conclui-se que a terapia utilizada apresenta eficácia nos controle de infestações por estes ácaros.
\end{abstract}

Descritores: ivermectina, Mus muscullus, Radfordia, Myocoptes, Demodex.

\section{ABSTRACT}

The use of laboratory animals in research is a practice commonly employed, but these studies may be affected by environmental and infectious conditions. The aim of this study was to report the mixed infestation by ectoparasites in mice (Mus muscullus) kept in an animal house and to evaluate a therapeutic protocol for the control of the parasites. Twenty animals showed dry fur, crusts, intense itching, red, humid and alopecic areas in the dorsal region of the body. Microscopic examination of the fur detected mites of the species Radfordia affinis, Myocoptes musculinus and Demodex sp. Rodents were separated in two groups: group A received $1 \%$ ivermectin diluted in water $\left(0,007 \mathrm{mg} \mathrm{ml}^{-1}\right)$ for five consecutive days and group B received only water. After 10 days of treatment, mites were not found in group A, although a greater number of parasites and skin lesions were found in the animals of group B. Based upon the results it is concluded that the therapy used was efficient in the control of the above mentioned mites.

Keywords: ivermectin, Mus muscullus, Radfordia, Myocoptes, Demodex. 


\section{INTRODUÇÃO}

A investigação biomédica ainda depende da utilização de animais de laboratório, sendo camundongos e ratos os mais comumente utilizados em experimentação. Trabalhos realizados com esses animais mostram que os mesmos podem ser afetados pelas condições ambientais e infecciosas, acarretando interferência em pesquisas [11,13]. Conforme a literatura brasileira, colônias de camundongos e de rato podem ser parasitados por ectoparasitos (Radfordia affinis, Myocoptes musculinus, Myobia musculi, Radfordia ensifera, Poliplax spinulosa e Poliplax serrata) e endoparasitos (Aspiculuris tetraptera, Tritrichomonas muris, Giardia muris, Entamoeba muris, Eimeria sp., Hexamastix muris, Trichosomoides crassicauda, Spironucleus muris, Syphacia obvelata, Syphacia muris e Hymenolepis nana) $[8,10]$.

Princípios ativos convencionais como os piretróides, organofosforados e as avermectinas são reportadas como eficazes medidas profiláticas e curativas para ácaros em camundongos de laboratório $[14,15]$. Ectoparasitoses podem interferir em pesquisas científicas, no entanto, não é comum causarem mortalidade em camundongos. Por isso, considerouse oportuno relatar a infestação mista por três ectoparasitos em camundongos (Mus muscullus) de biotério experimental e testar um protocolo terapêutico a fim de controlar a infestação.

\section{MATERIAIS E MÉTODOS}

Em um primeiro momento, três roedores que apresentavam lesões na pele foram analisados. Estes animais faziam parte de um grupo de 30 camundongos machos com dois meses de idade, mantidos em um biotério experimental no município de Santa Maria, Rio Grande do Sul, Brasil. É importante ressaltar que três deles já haviam morrido com lesões profundas e sangrentas. $\mathrm{Na}$ anamnese foi informado que as lesões iniciaram sete dias após os roedores terem sido introduzidos no ambiente e que a maravalha utilizada como cama não era esterilizada. Durante exame físico foi observado pelo seco, áreas de alopecia com lesões avermelhadas e úmidas, prurido intenso, além de crostas na região dorsal do corpo. Coletou-se pelos de todos os animais e foi realizado raspado cutâneo de 11 que apresentavam lesões de pele.
Baseado no diagnóstico parasitológico os animais foram divididos em dois grupos com 10 animais cada. Os animais do grupo A foram tratados com ivermectina $1 \%$ diluída em água na dose de 0,007 mg. $\mathrm{ml}^{-1}$ e oferecida por cinco dias consecutivos e os ratos do grupo B não foram tratados, grupo controle, e reavaliados após 10 dias do início do tratamento. Importante ressaltar que os animais foram mantidos em uma mesma sala experimental.

\section{RESULTADOS}

No presente estudo os ácaros encontrados nos camundongos foram identificados como pertencentes às espécies Myocoptes musculinus, Radfordia affnis e Demodex sp. As duas primeiras espécies estavam presentes em todos os camundongos, ao contrário da sarna Demodex que foi identificada apenas em 11 roedores que apresentavam lesões de pele profundas, sangrentas ou crostrosas.

Após 10 dias do início do tratamento, no grupo A não foram encontrados ácaros vivos ou mortos. As lesões sangrentas encontravam-se em processo de cicatrização. No entanto, no grupo B o número de ectoparasitos havia aumentado. As lesões de pele não regrediram e em quatro camundongos aumentaram consideravelmente ocasionando a morte destes roedores.

\section{DISCUSSÃO}

As lesões de pele, apresentadas pelos animais deste estudo já foram referenciadas em outros trabalhos, sendo que, camundongos parasitados pelas espécies $M$. musculinus e $R$. affinis, quando em elevada infestação, podem apresentar áreas de alopecia, escoriações na pele e dermatites, além de intenso prurido [2]. Conforme pesquisas, roedores parasitados por Demodex musculi podem apresentar dermatites [9]. Neste estudo, esse prostigmata encontrado nos raspados cutâneos pode ter sido decorrente da imunossupressão causada pelos demais acarinos, pois se sabe que a demodicose surge principalmente em animais debilitados ou predispostos geneticamente. Acredita-se que a severidade das lesões seja decorrente da infecção mista pelos três ácaros encontrados em número elevado, pois nos outros estudos estes parasitos foram encontrados em infecções individuais $[8,9,16,17]$.

Conforme a literatura, M. musculinus é um ácaro espécie-específica, comumente encontrado em 
camundongos de biotério no Brasil [4,8]. Esse parasito é cosmopolita, sendo reportado em roedores na Califórnia, Washington, Japão, Indonésia e França $[1,7,16,18,19]$. M. musculinus já foi encontrado em ratos selvagens da espécie Notomys alexis [12]. O gênero Radfordia apresenta ampla distribuição geográfica, sendo prevalente em camundongos da espécie $R$. affinis [3,8,16,17], mesma espécie encontrada no presente trabalho. No Brasil não se tem registro de parasitismo por Demodex sp. em M. musculus, sendo este estudo o primeiro caso. Em outros países ácaros das espécies Demodex flagellurus, Demodex agrarii e Demodex musculi já foram descritos [5,6,9].

A falta de barreiras sanitárias pode ter sido a causa do surto pelos ácaros no biotério experimental, pois a maravalha não era esterilizada e o biotério não tinha proteção para entrada de outros roedores. Pesquisa realizada no Brasil mostrou que grande parte das instituições não utiliza barreiras para controle de infecções, e que os programas de fiscalização sanitária de suas colônias são ineficientes, pois não são capazes de manter os animais sob condições saudáveis [8]. Neste estudo comprovou-se que os roedo- res já estavam parasitados quando chegaram ao biotério experimental, pois ao visitar o local de origem dos animais foi verificado o parasitismo de todos os camundongos.

O tratamento com ivermectina utilizado neste estudo teve eficácia de $100 \%$ no controle do parasitismo, assim como em outras pesquisas que utilizaram ivermectina e moxidectina em doses diferentes contra infestações por Myobia musculi e Myocoptes musculinus $[14,15]$. O protocolo terapêutico utilizado neste estudo foi aplicado no biotério de origem dos camundongos onde se obteve o mesmo sucesso no combate dos parasitos após 10 dias.

\section{CONCLUSÃO}

Com base nos resultados, concluímos que o protocolo utilizado a base de ivermectina é eficaz no controle destes ácaros. Acredita-se que a severidade das lesões produzidas pelos ectoparasitos seja decorrente da infestação mista, assim como a mortalidade de alguns animais não tratados. A ausência de barreiras sanitárias provavelmente foi a causa determinante para o parasitismo.

\section{REFERÊNCIAS}

1 Berkenkamp S.D. \& Wescott R.B. 1988. Arthropod transmission of Eperythrozoon coccoides in mice, Washington. Contemporary Topics in Laboratory Animal Science. 38(6): 398-401.

2 Besch-Williford C. \& Franklin C. 2007. Clinical parasitology of labotatory rodents and rabbtis., Disponível em: <http://www.radil-llc.com/docs/FELASA-ICLAS2007LabAnimalParasitology.pdf>. Acessado em 06/2009.

3 Bochkov A.V. \& Mironov S.V. 1998. Taxonomy of ticks of the genus Microtimyobia (Acariformes: Myobiidae: Radfordia) and their distribution on voles (Rodentia: Cricetidae: Arvicolinae). Parazitologiia. 32(4): 300-316.

4 Bressan M.C., Bressan M.C.R.V., Calgaro G.A., Alexandre S. \& Marques T. 1997. Prevalence of ecto and endoparasites in mice and rats reared in animalhouses. Brazilian Journal of Veterinary Research and Animal Science. 34(1): 86-90.

5 Bukva V. 1990. Transmission of Demodex flagellurus (Acari: Demodicidae) in the house mouse Mus musculus, under laboratory conditions. Experimental and Applied Acarology. 10(1): 53-60.

6 Bukva V. 1994. Demodex agrarii sp.n. (Acari: Demodecidae) from cerumen and the sebaceous glands in the ears of the striped field mouse Apodemus agrarius (Rodentia). Folia Parasitológica. 10(4): 305-311.

7 Durden L.A. \& Page B.F. 1991. Ectoparasites of commensal rodents in Sulawesi Utara, Indonesia, with notes on species of medical importance. Medical and Veterinary Entomology. 5(1): 1-7.

8 Gilioli R., Andrade L.A.G., Passos L.A.C., Silva F.A., Rodrigues D.M. \& Guaraldo A.M.A. 2000. Estudo de parasitos em colônias de ratos e de camundongos em biotérios brasileiros mantidos sob diferentes condições de barreiras sanitárias. Arquivo Brasileiro de Medicina Veterinária e Zootecnia. 52(1): 33-37.

9 Hill L.R., Kille P., Weiss D.A., Craig T.M. \& Coghlan L.G. 1999. Demodex musculi in the Skin of Transgenic Mice Texas, USA. Contemporary Topics in Laboratory Animal Science. 38(1): 13-18.

10 Hill N.J., Rose K., Deane E.M. \& Old J.M. 2007. Rodentolepis fraterna: The cause of mortality in a new host, the Spinifex hopping mouse (Notomys alexis). Contemporary Topics in Laboratory Animal Science. 85(1): 62-64.

11 Homberger F.R. \& Thomann P.E. 1994. Transmission of murine viruses and Mycoplasma in laboratory mouse colonies with respect to housing conditions. Laboratory Animals. 28(1): 113-120. 
12 Old J.M., Hill N.J. \& Deane E.M. 2007. Isolation of the mite Myocoptes musculinus Koch from the Spinifex hopping mouse (Notomys alexis). Laboratory Animals. 41(2): 292-295.

13 Pakes S.P., Lu Y.S. \& Meunier P.C. 1984. Factors that complicate animal research. In: Fox JG. (Ed). Laboratory animal medicine. New York: Academic Press, pp.649-665.

14 Papini R. \& Marconcini A. 1991. Treatment with Ivermectin in drinking water against Myobia musculi and Myocoptes musculinus mange in naturally infected laboratory mice. Angew. Parasitology. 32(1): 11-13.

15 Pullium J., Brooks W., Langley A. \& Huerkamp M.A. 2005. A single dose of topical moxidectin as an effective treatment for murine acariasis due to Myocoptes musculinus. Contemporary Topics in Laboratory Animal Science. 44(1): 26-28.

16 Reeves W.K. \& Cobb K.D. 2005. Ectoparasites of house mice (Mus musculus) from pet stores in South Carolina, USA. Comparative Parasitology. 72(2): 193-195.

17 Soliman S., Main A.J., MarzoukA.S. \& Montasser A.A. 2001. Seasonal studies on commensal rats and their ectoparasites in a rural area of Egypt: The relationship of ectoparasites to the species, locality, and relative abundance of the host. Journal of Parasitology. 87(3): 545-553.

18 Sugiura K., Sugiura M. \& Hayakawa R. 2002. Study of the patch test reactions to Myocoptis musculinos (kekuidani) of NC/F mice (atopic model mice), Japão. Clinical and Experimental Studies 1(2): 87-91.

19 Zenner L. \& Regnault J.P. 2000. A retrospective study of the microbiological and parasitological status of laboratory rodents in France. Journal of experimental animal science. 40(4): 211-222. 